\title{
In-vitro antibacterial activity of commercially available hand sanitizers
}

\author{
Farwa Ayaz, Fatima Rauf, Rabia Azeem, Muhammmad Azam Khan*, \\ Ayesha Tahir and Kayanat Bibi \\ Department of Microbiology, Govt. Post Graduate College Mandian, Abbottabad-Pakistan \\ *Corresponding author's email: microbiologistazam@gmail.com \\ Citation \\ Farwa Ayaz, Fatima Rauf, Rabia Azeem, Muhammmad Azam Khan, Ayesha Tahir and Kayanat Bibi. In-vitro \\ antibacterial activity of commercially available hand sanitizers. Pure and Applied Biology. Vol. 9, Issue 1, \\ pp1069-1076. http://dx.doi.org/10.19045/bspab.2020.90112
}

\begin{tabular}{llll}
\hline Received: 26/10/2019 & Revised: 02/01/2020 & Accepted: 08/01/2020 & Online First: 25/01/2020 \\
\hline
\end{tabular}

\section{Abstract}

Hands are the prime means of transmission of microbes and the subsequent cause of nosocomial infections. To overcome the negative effect of microbial burden in health care settings, hand sanitizers are recommended for hand disinfection. Keeping this view, the present study was designed to demonstrate the antibacterial activity of fifteen hand sanitizers available in the market against the standard bacterial isolates (Staphylococcus aureus, Escherichia coli, Staphylococcus epidermidis and Pseudomonas aeruginosa) by using Kirby Bauer disc diffusion method. Their efficacy was checked at two concentrations (100\% and 50\%). Among the fifteen sanitizers tested, three of them Biotol $=75 \%$, Antibacterial hand gel $=75 \%$ and Hiclean $=62.5 \%$ were found to be the most effective. Other sanitizers such as Purell , Enliven, Lifebuoy, Rivaj were seen in the efficacy range of $12.5 \%-25 \%$ while no activity $(0 \%)$ was observed in antiseptics Carex, Safeguard, Blue+King, Dial, Dettol, Cool and cool, Infectiguard and Newlife against all the tested bacterial isolates. Our study concluded that sanitizer Biotol, Antibacterial hand gel and Hiclean exhibited maximum efficacy at both concentrations and thus fulfilled the claim of their manufacturer as germicidal.

Keywords: Antiseptics; Antibacterial; Hand hygiene; Hand sanitizers; Susceptibility

\section{Introduction}

Hands are the prime means of transmission of pathogens [1]. That are the subsequent cause of nosocomial infections and food borne illness [2]. Hand hygiene usually refers to different procedures of eliminating or killing microorganisms present on hands, by either hand washing or sanitizing $[3,4]$. It is renowned as an efficient, cost-effective and easy to perform practice that not only reduce the cross transmission of nosocomial infections but also the burden related with these infections $[3,5]$.

Hand sanitizers (HS) can be termed as "an alternative to hand washing [6]. When opportunities are not available to access portable water or to wash hands with soap and warm water" [7]. HS are available in diversity of forms (gel or liquid) and formulations such as alcoholic and nonalcoholic [8,9]. Antimicrobial property of the antiseptics is due to their active ingredients. Among alcoholic sanitizers, ethyl alcohol and isopropyl are the common active ingredients while propylene glycol, glycerin, polyacrylic acid are the some inactive ingredients [8]. Beside these, Nonalcoholic hand rubs are also available based on benzalkonium chloride or povidoneiodine chlorinated aromatic compound triclosan and pyroglutamic acids, but studies estimating these are limited. Benzalkonium chloride is well known to have limited activity against gram-negative 
bacteria as compared to alcoholic hand sanitizers and is susceptible to contamination by these bacteria [10].

The mechanism of action of the sanitizers is more or less similar to denaturing the protein of microbes. Lipids are also denatured by alcohol and causes dehydration in bacteria. On the other hand, Benzalkonium Chloride has the ability to denature cell membrane and protein, and effective against wide range of organisms [11].

The present study was conducted to evaluate the efficacy of different brands of hand rubs against some skin colonizing bacteria. In order to provide data to the public, surgeons, physicians and nursing staff for the selection of better and protective hand antiseptics against disease causing microbes because all the products advertised to the community as germicidal are not efficient in decreasing microbial concentration on hands. Although, the companies claim their products are effective against "germs and harmful bacteria" by $99.9 \%$. However, there is a dire need of study for the verification of these claims.

\section{Materials and methods Study area}

This study was done in the Veterinary Research Institute and Disease Investigation Centre (VRDIC) District Abbottabad, Pakistan.

\section{Sample collection}

Fifteen different brands (Dial, Hi clean, Carex, Biotol, Dettol, Purrel, Safeguard, Infectiguard, Rivaj UK, Lifebuoy, Antibacterial hand gel, Blue king, Enliven, Cool and cool, New life) of foam and gel based hand sanitizers were purchased from Habib Chemist and Shaheen Chemist, District Abbottabad. Expiry dates and Batch number were noted before conducting the study.

\section{Preparation of dilution}

The efficacy of sanitizers was checked at $100 \%$ and $50 \%$ concentrations. For the preparation of $50 \%$ concentration of sanitizers, $2 \mathrm{ml}$ of distilled water was added into a test tubes followed by $2 \mathrm{ml}$ sanitizers. Then all the tubes were vortex for proper mixing of water and sanitizers. Each sample was then put into separate petri plates labelled with their specific name.

\section{Isolation and identification of organisms}

The products were tested against the following isolates $E$. coli, $P$. aeruginosa, $S$. aureus and $S$. epidermidis. Sterile cotton swabs damped in normal saline were used to collect sample. For $S$. aureus and $S$. epidermidis, samples were collected from skin of arms and hands while transient bacteria ( $P$. aeruginosa and $E$. coli) were isolated from contaminated hands of volunteer students and wound of patient. Samples were cultured on MacConkey agar and nutrient agar and then incubated for 24 hours at $37^{\circ} \mathrm{C}$. Gram staining for each isolate was performed to categorize the bacteria as gram positive or gram negative. For the confirmation and studying of their biochemical characteristics, these cultures were subjected to a series of biochemical tests (Catalase, and Coagulase, Oxidase and IMVIC). $S$. epidermidis was further confirmed by checking its sensitivity against Novobiocin antibiotic. These isolates were maintained in nutrient broth by adding $20 \%$ glycerol and stored it at $80^{\circ} \mathrm{C}$ for further use.

The antibacterial activity of sanitizers checked by using Kirby Bauer disc diffusion method [12]. Sterile filter paper discs $(9 \mathrm{~mm})$ were soaked in sanitizer for $2 \mathrm{hrs}$ in order to get full saturation. Sterile swab sticks were used to carpet spread the standardized culture ( $0.5 \mathrm{Mc}$ Farland) on to the surface of already prepared Mueller Hinton agar plate and allowed to dry for 10 to 15 minutes. Discs were kept on the surface of lawn culture. Discs soaked in distilled water were used as a negative control and ethyl alcohol as positive control. Incubation was carried out for $24 \mathrm{hrs}$ at $37^{\circ} \mathrm{C}$. Each experiment was repeated in triplicates. The antibacterial activity was analyzed by measuring the diameter of inhibition zone and recorded in millimeters (mm). 


\section{Results}

Table 1 shows the susceptibility pattern of microorganisms against highly effective and least effective sanitizers with their zone of inhibition and standard error at $100 \%$ and $50 \%$ concentration.

Table 1. Susceptibility pattern of the microorganisms using sanitizers at $100 \%$ and $50 \%$ concentration by disc diffusion method

\begin{tabular}{|c|c|c|c|c|c|c|}
\hline \multirow{2}{*}{$\begin{array}{l}\text { Sanitizers } \\
\text { Name }\end{array}$} & \multirow[b]{2}{*}{ Active Ingredients } & \multirow{2}{*}{$\begin{array}{c}\text { Concentrations } \\
(\%)\end{array}$} & \multicolumn{4}{|c|}{ Zone Diameter of Inhibition(mm) with SE } \\
\hline & & & $\begin{array}{c}\text { S. } \\
\text { aureus }\end{array}$ & E. coli & P. aeruginosa & $\begin{array}{c}\text { S. } \\
\text { epidermidis }\end{array}$ \\
\hline \multirow{2}{*}{ Carex } & \multirow{2}{*}{$\begin{array}{l}\text { Ethyl alcohol, triethanol } \\
\text { amine, triclosan }\end{array}$} & 50 & 0 & 0 & 0 & 0 \\
\hline & & 100 & 0 & $14 \pm 0.3$ & 0 & 0 \\
\hline \multirow{2}{*}{ Hi clean } & \multirow{2}{*}{$\begin{array}{c}\text { Cationicsurfactant, } \\
\text { nonionicsurfactant, } \\
\text { amphoteric } \\
\text { surfactant,polybiguanide }\end{array}$} & 50 & $27 \pm 0.3$ & $13 \pm 0.9$ & $12 \pm 0.6$ & $22 \pm 0.3$ \\
\hline & & 100 & $26 \pm 0.7$ & $15 \pm 1$ & $13 \pm 0.6$ & $24 \pm 0.6$ \\
\hline \multirow{2}{*}{ Biotol } & \multirow{2}{*}{$\begin{array}{c}\text { Ethylalcohol, } \\
\text { carbomer,triethanol } \\
\text { amine, propilen glycol, } \\
\text { triclosan }\end{array}$} & 50 & $47 \pm 1.2$ & $36 \pm 0.9$ & $13 \pm 0.6$ & $46 \pm 0.6$ \\
\hline & & 100 & $50 \pm 1.1$ & $36 \pm 0.3$ & $13 \pm 0.9$ & $48 \pm 0.9$ \\
\hline \multirow{2}{*}{ Dettol } & \multirow{2}{*}{$\begin{array}{c}\text { Alcohol denat, water } \\
\text { PEG/PPG- } \\
\text { 17/6,copolymer }\end{array}$} & 50 & 0 & 0 & 0 & 0 \\
\hline & & 100 & 0 & $12 \pm 0.9$ & 0 & 0 \\
\hline \multirow{2}{*}{ Purell } & \multirow{2}{*}{ Ethylalcohol $70 \%$} & 50 & 0 & 0 & 0 & 0 \\
\hline & & 100 & $18 \pm 0.9$ & $11 \pm 0.3$ & $10 \pm 0.9$ & 0 \\
\hline \multirow{2}{*}{ Safeguard } & \multirow{2}{*}{$\begin{array}{c}\text { Alcohol denat, acqua, } \\
\text { glycerine,isopropyl } \\
\text { alcohol, }\end{array}$} & 50 & 0 & 0 & 0 & 0 \\
\hline & & 100 & $13 \pm 0.1$ & $11 \pm 0.6$ & $13 \pm 0.3$ & $12 \pm 0.3$ \\
\hline \multirow{2}{*}{ Dial } & \multirow{2}{*}{ Ethyl alcohol 62\% } & 50 & 0 & 0 & 0 & 0 \\
\hline & & 100 & 0 & 0 & 0 & 0 \\
\hline \multirow[b]{2}{*}{ Enliven } & \multirow{2}{*}{$\begin{array}{c}\text { Alcoholdenat, } \\
\text { acqua,propylene glycol, } \\
\text { carbomer, }\end{array}$} & 50 & 0 & 0 & 0 & 0 \\
\hline & & 100 & $22 \pm 0.6$ & $12 \pm 0.1$ & $11 \pm 0.7$ & 0 \\
\hline \multirow{2}{*}{ Blue+King } & \multirow{2}{*}{ Ethyl alcohol 52\% } & 50 & 0 & 0 & 0 & 0 \\
\hline & & 100 & $14 \pm 0.6$ & $13 \pm 1.4$ & 0 & $14 \pm 0.8$ \\
\hline \multirow{2}{*}{ Rivaj } & \multirow{2}{*}{$\begin{array}{c}\text { Alcohol,acqua, } \\
\text { carbomer, triclosan }\end{array}$} & 50 & 0 & 0 & 0 & 0 \\
\hline & & 100 & $15 \pm 0.3$ & $15 \pm 0.9$ & $12 \pm 0.4$ & 0 \\
\hline \multirow{2}{*}{ Lifebuoy } & \multirow{2}{*}{ Ethyl alcohol } & 50 & $14 \pm 0.6$ & 0 & 0 & 0 \\
\hline & & 100 & $16 \pm 0.6$ & 0 & 0 & 0 \\
\hline \multirow{2}{*}{$\begin{array}{l}\text { Antibacterial } \\
\text { hand gel }\end{array}$} & \multirow{2}{*}{$\begin{array}{l}\text { Alcohol, denat, aqua, } \\
\text { propyleneglycol, } \\
\text { triclosan, carbomer }\end{array}$} & 50 & $35 \pm 0.8$ & $25 \pm 0.8$ & 0 & $22 \pm 0.3$ \\
\hline & & 100 & $36 \pm 0.3$ & $36 \pm 0.8$ & 0 & $25 \pm 0.3$ \\
\hline \multirow[b]{2}{*}{ Cool and cool } & \multirow{2}{*}{$\begin{array}{l}\text { Aqua, carbomer, Ethyl } \\
\text { alcohol, triethanolamine, } \\
\text { glycerine }\end{array}$} & 50 & 0 & 0 & 0 & 0 \\
\hline & & 100 & 0 & 0 & 0 & 0 \\
\hline & & 50 & 0 & 0 & 0 & 0 \\
\hline Intectiguard & Ethyl alcohol & 100 & 0 & 0 & 0 & 0 \\
\hline & & 50 & 0 & 0 & 0 & 0 \\
\hline New life & Ethanol $10 \%$ & 100 & 0 & 0 & 0 & 0 \\
\hline
\end{tabular}

Key; SE $=$ Standard Errors

Susceptibility pattern of microorganisms against highly effective sanitizers at $100 \%$ concentration

According to the results, three out of fifteen hand sanitizers that were the subject of this study showed the maximum efficacy profiles as shown in (Figure 1). It shows that sanitizer Biotol, Antibacterial hand gel and Hiclean were the most potent having highest efficacy against the three isolates: 
S. aureus, E. coli and S. epidermidis while least (Biotol and Hiclean) and no (Antibacterial Hand gel) activity against $P$. aeruginosa.

Sensitivity pattern of the microorganisms to other sanitizers at $100 \%$ concentration
Other sanitizers (Carex, Blue+king, Purell, Enliven, Safeguard, Lifebuoy, carex and Rivaj) showed variable susceptibility against microorganisms as shown in the (Figure 2). The test

Organisms were resistant to the sanitizers D (Dettol), G (Dial), M (Cool and cool), N (Infectiguard) and O (Newlife).

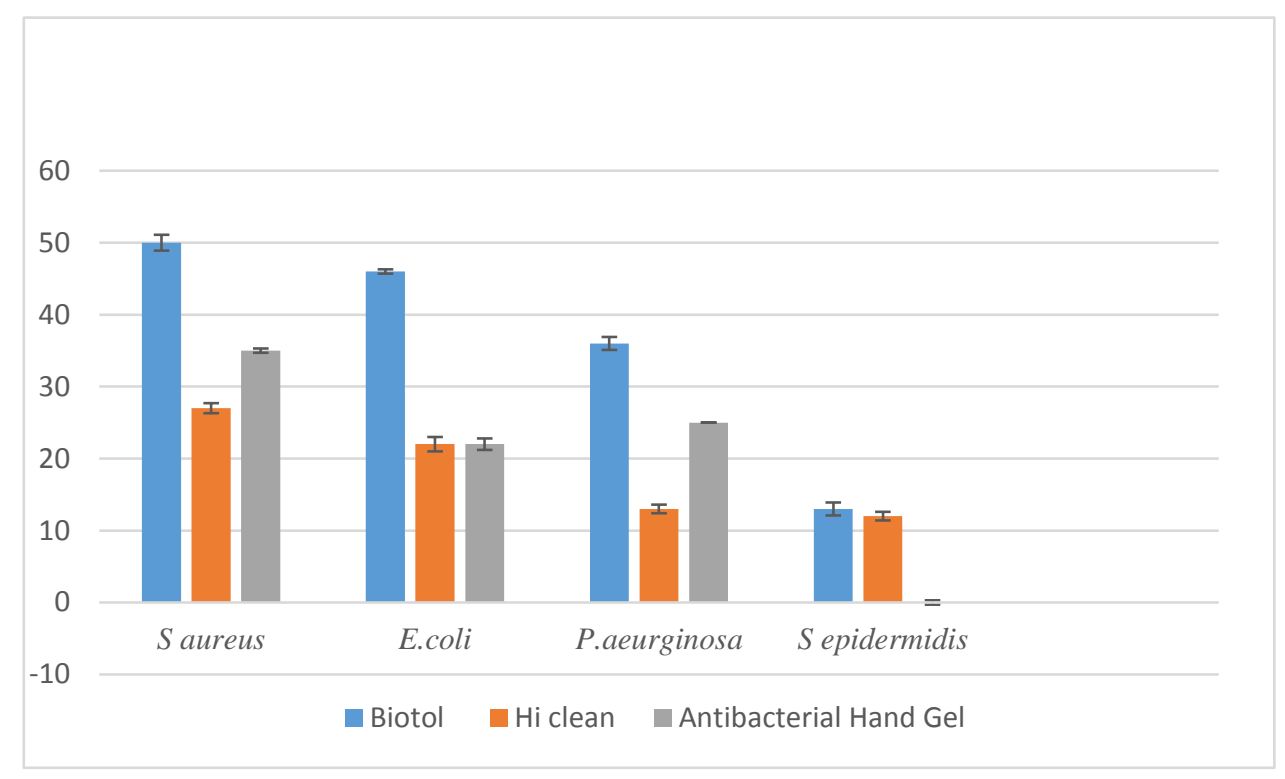

Figure 1. Susceptibility pattern of microorganisms against sanitizers hi-clean, biotol and antibacterial hand gel at $100 \%$ concentration

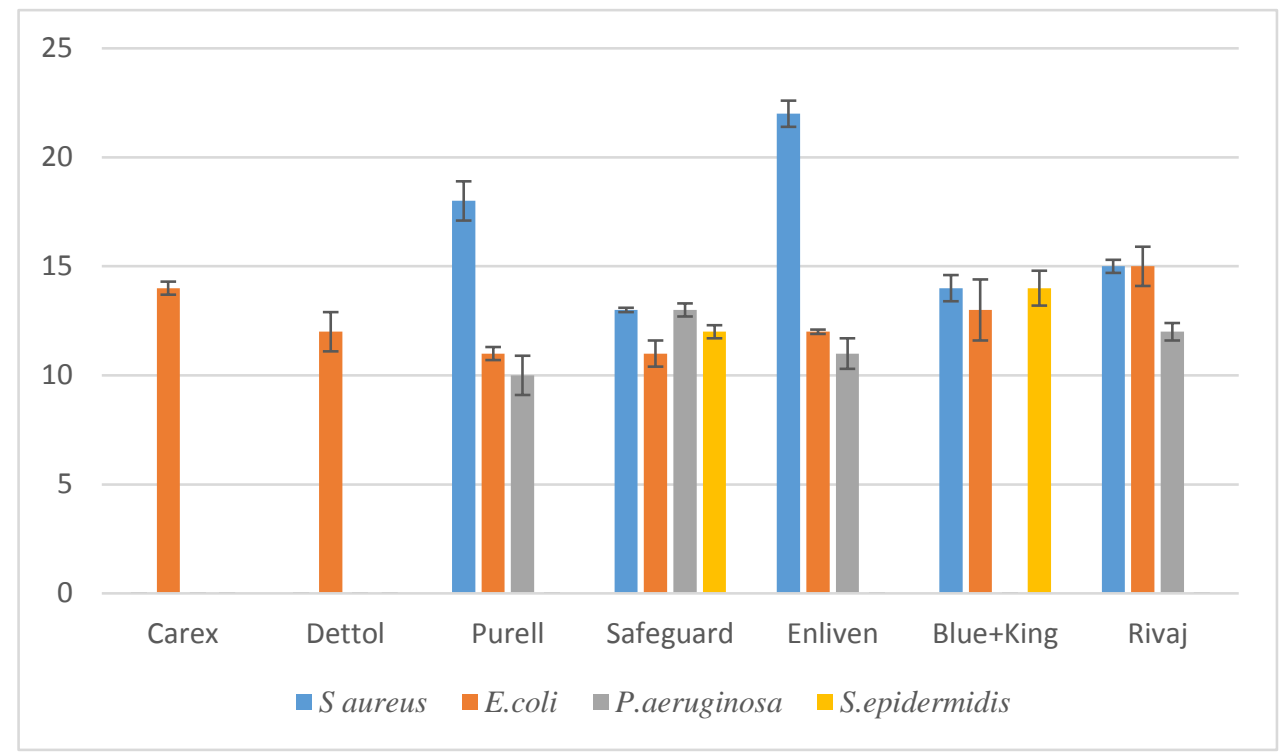

Figure 2. Sensitivity pattern of the microorganisms to other sanitizers at $100 \%$ concentration

Susceptibility of microorganisms against sanitizers at $50 \%$ concentration
Our findings indicate that, when the product efficacy was checked at 50\% concentration, the same inhibitory activity 
was observed in sanitizer Biotol, Hiclean, Lifebuoy and Antibacterial hand gel as observed at $100 \%$ concentration.

Mostly, all the sanitizers (Carex, Dettol, Purell, Safeguard, Dial, Enliven, Rivaj UK, Blue+king, Cool and cool, Infectiguard, Newlife) did not show any zone against any tested organisms at $50 \%$ concentration which means that by decreasing the concentration of the product the product activity decreases against all the tested isolates.

Susceptibility percentage of isolates to the sanitizers at $100 \%$ concentration
Susceptibility percentage of isolates were also calculated shown in the (Figure 3). At $100 \%$ concentration, the results indicated that among gram-positive organism, $S$. aureus was resistant to $40 \%$ and susceptible to $46.6 \%$ of hand antiseptics and $S$. epidermidis was resistant to $66.6 \%$ and susceptible to $20 \%$ of the sanitizers evaluated. Among gram-negative organisms, E. coli was resistant to $40 \%$ and susceptible to $20 \%$ of the sanitizers and $P$. aeruginosa was resistant to $66.6 \%$ and susceptible to $6.66 \%$ of all the antiseptics used in the study.

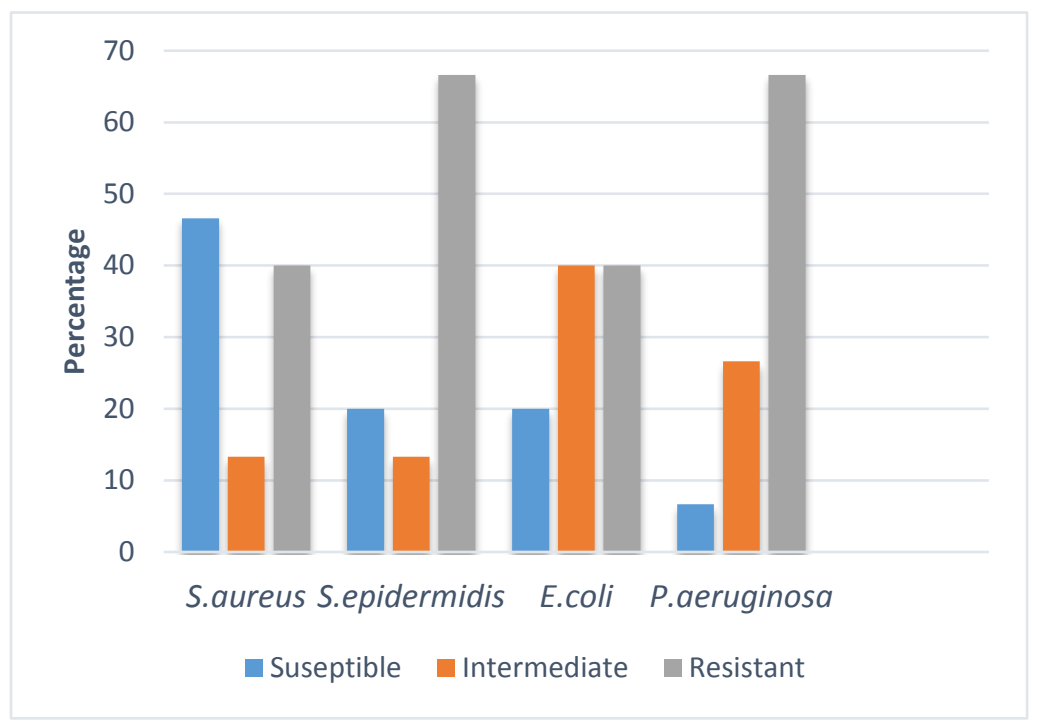

Figure 3. Susceptibility percentage of microorganisms to different hand sanitizers at $100 \%$ concentration

\section{Susceptibility percentage of isolates to the sanitizers at $50 \%$ concentration}

Susceptibility percentage was also calculated at $50 \%$ concentration shown in (Figure 4). The results indicated that among gram-positive organisms, $S$. aureus was resistant to $73.3 \%$ and susceptible to $20 \%$ of the sanitizers, $S$. epidermidis was resistant to $80 \%$ and susceptible to $20 \%$ of all the antiseptics that are evaluated in the study. Among gram-negative organisms, $E$. coli was resistant to $80 \%$ and susceptible to $13.3 \%$ and $P$. aeruginosa was resistant to $86.6 \%$ and not susceptible to any of the hand sanitizers used in the study. 


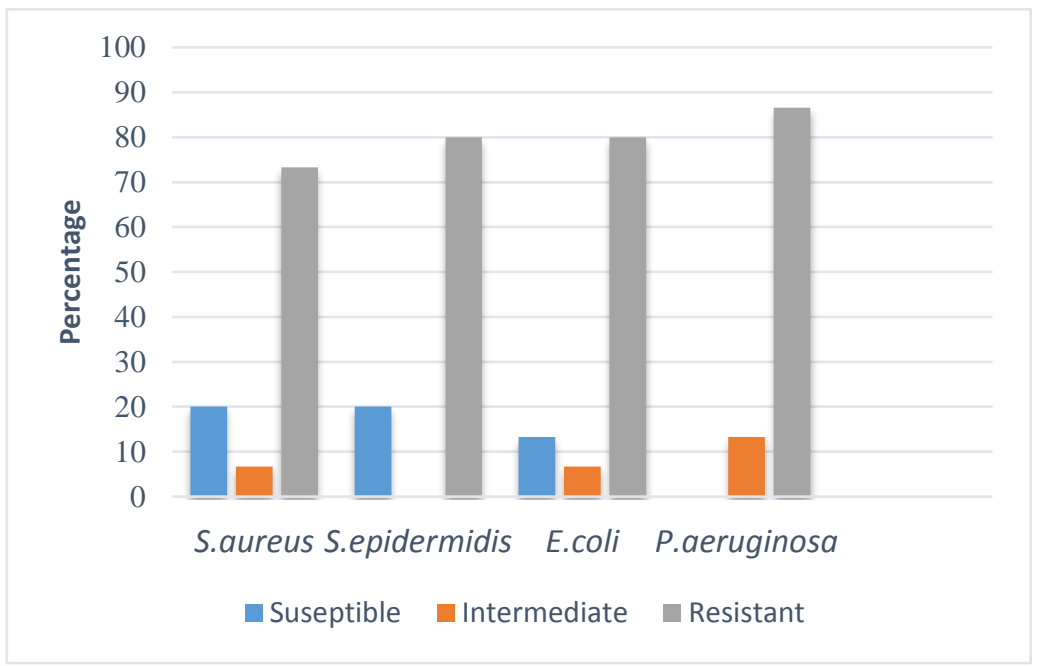

Figure 4. Susceptibility percentage of microorganisms to different sanitizers at $50 \%$ concentration

\section{Discussion}

Human skin provides appropriate growth conditions and nutrients for normal flora as well as for pathogenic microorganisms present on it [13]. Microbial infection in the environment is increasing alarmingly [14]. To overcome the negative effect of microbial burden in healthcare settings, hand sanitizers are suggested in addition to plain hand washing [9].

To access the antibacterial activity and to check the dilution effects, fifteen antiseptics were evaluated using agar well diffusion method. Following bacterial isolates i.e., $S$. aureus, $E$. coli, $S$. epidermidis and $P$. aeruginosa were used as test organisms. Most of the sanitizers (Hiclean, Biotol, Antibacterial hand gel, Purell, Enliven, Rivaj and Lifebuoy) used in the current study were effective at $100 \%$ concentration for $S$. aureus followed by $S$. epidermidis (Hiclean, Biotol, Antibacterial hand gel), E. coli (Hiclean, Biotol, Antibacterial hand gel) and almost all the sanitizers were not active against $P$. aeruginosa. This is possibly due to the resistant nature of $P$. aeruginosa as it has been reported unaffected to a number of antibiotics and can persist in sanitizers.

Our results corroborate with the findings of [10] in which the inhibition zone for Lifebuoy against $S$. aureus was (12mm) and it showed a disagreement with the findings of [15] who observed that sanitizer Blue+King as not active against $S$. aureus, $P$. aeruginosa, and E. coli.

Hayat and Munnawar analysed that Dettol, Dial and Carex were effective against $S$. aureus, $P$. aeruginosa, E. coli that disagrees with our findings in which no zone of inhibition was seen against these tested isolates. Our results corroborate the findings of [16] who reported that Dettol sanitizer did not inhibit the growth $S$. epidermidis, $S$. aureus and $P$. aeruginosa. On the contrary, the result of this study does not support the findings of [14] that showed that Dettol hand sanitizer was effective against S. aureus, S. epidermidis with zones of inhibition of $5 \mathrm{~mm}$ against each of them. The conflicting results from other studies might be due to differences in the methodology they had used, different instrumentation, difference in the batch numbers of the products, even varying in tiny ways (proper handling, study time, study area).

The results were consistent with the findings of [17] who observed that Dettol sanitizer was ineffective against $S$. aureus, and $P$. aeruginosa and in agreement with the findings of [15] where Purell, Safeguard and $\mathrm{Cool}$ and Cool were ineffective against E. coli and P. aeruginosa. 
Sanitizer Hiclean, Biotol and Antibacterial hand gel showed the maximum zones of inhibition against the three isolates ( $S$. aureus, $S$. epidermidis and E. coli). However, the exact comparison of these antiseptics could not be done with other studies due to absence of convincing scientific literature.

Susceptibility percentage was also calculated against the tested microorganisms at $100 \%$ concentration. $S$. aureus (46.6\%), S. epidermidis (20\%), E. coli $(20 \%)$ and $P$. aeruginosa (66.6\%) susceptible to all the antiseptics used in the study. Previously variable level of activity of antiseptics available in the market, have been reported. Sharif and Ansari [18] analysed the effectiveness of a number of hand sanitizers and found that among the tested products only one was efficient against $6.5 \%$ of the isolates tested. Another recent study carried out in Kenya [19] revealed that $25 \%$ of tested products were showing their activity against only $33 \%$ of the tested organisms and an indefinite number of the antiseptics were not effective at all against any of the test organism.

Results checked at $50 \%$ concentration in which almost not all the sanitizers except Sanitizer Hiclean, Biotol and Antibacterial hand gel exhibited any activity against any tested organism, which supports the findings of [17] who showed that antibacterial activity of most of the hand sanitizers decreases with increase in dilution or decrease in its concentration.

Our study had few limitations as well that we did not test all the known hand sanitizers at District Abbottabad for the reason that they were not available in the market at that time. To our certain knowledge, we collected all the sanitizers, which were available at that time. One of the shortcomings of our study was that we had no knowledge of the active ingredient that are used in different hand sanitizers.

Our study recommends that effectiveness of different products should be checked properly before it is commercialized and sent to the market. Manufacturer and regulatory authorities should uphold strict control through the quality and effectiveness of these products and the second most important thing is that consumer must not blindly trust the manufacturer claims as some companies' claims that their products are $99.9 \%$ germicidal but they are not so efficient. Therefore, we recommend that consumers should have prior knowledge of the products effectiveness.

\section{Conclusion}

After testing the activity of fifteen brands of hand sanitizers (alcoholic and nonalcoholic), the results showed that two alcoholic antiseptics (Biotol and Antibacterial hand gel) possessed the highest antibacterial activity, as all the tested isolates were sensitive to them. Among non-alcoholic sanitizers, Hi clean showed the best results while the other sanitizers showed the variable degree of activity. Apart from these findings, these products do not fulfill the claim of their manufacturer as having $99.99 \%$ germicidal.

\section{Authors' contributions}

Conceived and designed the experiment: MA Khan, performed the experiment: $F$ Ayaz, F Rauf \& R Azeem, Analyzed the data: F Ayaz, F Rauf, R Azeem, K Bibi \& A Tahir, Contributed materials/ analysis tools: F Ayaz \& F Rauf, Wrote the paper: F Ayaz, F Rauf \& R Azeem.

\section{Acknowledgement}

We are highly thankful to Veterinary Research Institute and Disease Investigation Centre (VDRIC) who provided the space and facilitate us in conducting the research.

\section{References}

1. Kolhapure SA (2004). Evaluation of the antimicrobial efficacy and safety of purehands herbal hand sanitizer in hand hygiene and on inanimate objects. Antiseptic 101(2): 55-57.

2. Oranusi SU, Dahunsi SO, Owoso OO \& Olatile T (2013). Microbial profiles of Hands, Foods, Easy contact surfaces and Food contact surfaces: A case study of a University Campus. Nov Int J Biotech Bio 2(1): 30-8. 
3. Pittet D, Allegranzi B, Sax H, Dharan S, Pessoa-Silva CL, Donaldson L \& Boyce JM (2006). Evidence-based model for hand transmission during patient care and the role of improved practices. Lancet infect Dis 6(10): 641-652.

4. Zapka C, Leff J, Henley J, Tittl J, De Nardo E, Butler M, Griggs R, Fierer N, Edmonds \& Wilson S (2017). Comparison of standard culture-based method to culture-independent method for evaluation of hygiene effects on the hand microbiome. MBio. 8(2):e0009317.

5. Haas JP \& Larson EL (2007). Measurement of compliance with hand hygiene. JHI 66(1): 6-14.

6. Pickering AJ, Davis J, Blum AG, Scalmanini J, Oyier B, Okoth G, Breiman RF \& Ram PK (2013). Access to waterless hand sanitizer improves student hand hygiene behavior in primary schools in Nairobi, Kenya. Am J Trop Med Hyg 89(3): 411-418.

7. Centers for Disease Control and Prevention (2015). Handwashing. Show me the science when to use hand sanitizer. Retrieved from http://www.cdc.gov/handwashing/show -methe- science-hand-sanitizer.html

8. Ikegbunam MN, Metuh RC, Anagu LO \& Awah NS (2013). Antimicrobial activity of some cleaning products against selected bacteria. IRJPAS 3: 1335.

9. Boyce JM \& Pittet D (2002). Guideline for hand hygiene in health-care settings: recommendations of the Healthcare Infection Control Practices Advisory Committee and the HICPAC/SHEA/APIC/IDSA Hand Hygiene Task Force. Infect Control Hosp Epidemiol 23(S12): S3-40.

10. Ali YA (2015). To study the effect of hand sanitizers used in kingdom of Saudi Arabia against the common bacterial pathogens. IRJNAS 2(2): 2349-4077.
11. Dixit PP, MR \& Dhasmana DC (2014). Alcohol Based Hand Sanitizers: Assurance and Apprehensions Revisited. RJBBSC 5(1): 558

12. Bauer AW, Kirby WM, Sherris JC \&Turck M (1996). Antibiotic susceptibility testing by a standardized single disk method. Am J Clin Pathol 45(4_ts): 493-6.

13. Cogen AL, Nizet V \& Gallo RL (2008). Skin microbiota: a source of disease or defence. Br J Dermatol 158(3): 442-455.

14. Kimura AC, Johnson K, Palumbo MS, Hopkins J, Boase JC, Reporter R, Goldoft M, Stefonek KR, Farrar JA, Van Gilder TJ \& Vugia DJ (2004). Multistate shigellosis outbreak and commercially prepared food, United States. Emerg Infect Dis 10(6): 1147.

15. Hayat A \& Munnawar F (2016). Antibacterial effectiveness of commercially available hand sanitizers. Int J Biol Biotech 13(3): 427-431.

16. Ichor T, Aondoakaa EM \& Ebah EE (2018). Comparative Studies on the Antibacterial Activity of Alcohol-Based Hand Sanitizers Against Bacteria Isolates from the Hands of Undergraduate Students of University of Agriculture. Makurdi J Clin Case Rep 8(1143):2.

17. Tambekar DH, Shirsa SD, Kakde SR \& Ambekar KB (2009). Hand hygiene and health: an epidemiological study of students in Amravati. Afr J Infect Dis 3(1).

18. Sharif M \& Ansari F (2015). Hand Sanitizers: Efficiency against Microbes from Currency Notes and Coins in Local Circulation. Pak J Mol Med 2(2): 75-83.

19. Oke MA, Bello AB, Odebisi MB, ElImam AA \& Kazeem MO (2013). Evaluation of antibacterial efficacy of some alcohol-based hand sanitizers sold in Ilorin (North-Central Nigeria). J Life Sci 15(1): 111-117. 